This is a post-peer-review, pre-copyedit version of an article published in Journal of Business Ethics. The final authenticated version is available online at: http://dx.doi.org/10.1007/s10551-017-3541-3. 
Explaining helping behavior in the workplace: The interactive effect of family-to-work conflict and Islamic work ethic

\author{
Dirk De Clercq \\ Goodman School of Business \\ Brock University \\ St. Catharines, Ontario L2S 3A1, Canada \\ ddeclercq@brocku.ca \\ Zahid Rahman \\ Alberta School of Business \\ University of Alberta \\ Edmonton, Alberta T6G 2R6, Canada \\ zahid@ualberta.ca \\ Inam UI Haq \\ Faculty of Management Sciences \\ Riphah International University \\ Lahore, Pakistan \\ inamulhaq27@gmail.com
}

Paper accepted for Journal of Business Ethics 


\title{
Explaining helping behavior in the workplace: The interactive effect of family-to-work conflict and Islamic work ethic
}

\begin{abstract}
Drawing from conservation of resources theory, this study investigates the interactive effect of employees' family-to-work conflict and Islamic work ethic on their helping behavior, theorizing that the negative relationship between family-to-work conflict and helping behavior is buffered by Islamic ethical values. Data from Pakistan reveal empirical support for this effect. Organizations whose employees suffer resource depletion at work because of family obligations can still enjoy productive helping behaviors within their ranks, to the extent that they support relevant work ethics.
\end{abstract}

Keywords: helping behavior; family-to-work conflict; Islamic work ethic, conservation of resources theory 


\section{Introduction}

Business ethics research acknowledges the importance of employee behaviors designed to help others, even when that behavior is not part of their formal job descriptions (Deckop, Cirka, \& Andersson, 2003; Tang, Sutarso, Wu Davis, Dolinski, Ibrahim, \& Wagner, 2008). Such helping behavior is a type of organizational citizenship behavior (OCB), in that employees go out of their way to assist other organizational members in the successful execution of their jobs (Organ, 1988; Tang et al., 2008). Helping behavior contributes to not only peer performance but also organizational effectiveness and employees' own well-being. To the extent that employees engage in such behaviors, they enhance the quantity and quality of peer performance (Podsakoff, Ahearne, \& MacKenzie, 1997), improve group performance (Bachrach, Powell, Collins, \& Richey, 2006), increase the organization's competitive advantage (Borman \& Motowidlo, 1993), and enjoy higher levels of relationship satisfaction for themselves (Hoption, 2016). Moreover, the tendency to be a "good soldier" (Peloza \& Hassay, 2006) and voluntarily reach out to other organizational members to help them complete their job tasks has an important ethical component, in that the notion of being "good" stems from employees' values and ethics (Turnispeed, 2002). Research in the realm of business ethics thus is interested in determining which factors can promote or threaten the likelihood that employees undertake beneficial helping behaviors (Deckop et al., 2003; Tang et al., 2008).

Prior research addresses different factors that can enable employees' helping behavior, including intrinsic and prosocial motives (Choi \& Moon, 2016; Tang et al., 2008), selfenhancement (Seo \& Scammon, 2014), transformational leadership (Zhu \& Akhtar, 2014), positive treatment by coworkers (Deckop et al., 2003), and group cohesion and cooperation (Liang, Shih, \& Chiang, 2015; Ng \& Van Dyne, 2005). Alternatively, negative factors that may 
steer employees away from helping behaviors include monetary-driven motives (Tang et al., 2008), excessive task conflict (Ng \& Van Dyne, 2005), and open conflict norms (Rispens, 2009). Another important factor is employees' perceptions of family-to-work conflict, which arise when family responsibilities and demands interfere with their work (Netemeyer, Boles, \& McMurrian, 1996). High levels of family-to-work conflict might deplete their resource bases, leaving employees unable to execute their regular job tasks (Nohe, Michel, \& Sonntag, 2014; Witt \& Carlson, 2006; Zhang, Griffeth, \& Fried, 2012), let alone direct their energy toward voluntary activities to help other organizational members. Previous evidence indicates a negative effect of family-to-work conflict on task citizenship behavior, citizenship behaviors directed at individuals (Beham, 2011), and OCB in general (Bragger, Rodriguez-Srednicki, Kutcher, Indovino, \& Rosner, 2005), and a meta-analysis affirms the negative relationship between family-to-work conflict and OCB (Amstad, Meier, Fasel, Elfering, \& Semmer, 2011). What extant research has not addressed fully, however, is how the harmful effect of family-to-work conflict might be contained (Witt \& Carlson, 2006).

Therefore, the primary research question that drives this research is how employees' Islamic work ethic, or the extent to which they embrace Islamic ethical values in their work (Ahmad, 2011; Yousef, 2001), might influence the negative relationship between family-to-work conflict and helping behaviors. An Islamic work ethic emphasizes diligent effort, collaboration, creativity, and morally responsible conduct (Ali \& Al-Owaihan, 2008). Islamic ethical values are deeply connected with how Muslims live their daily lives, including the decisions they make at work, such that actions in the workplace are judged through the lens of these religious values (Khan, Abbas, Gul, \& Raja, 2015). Our consideration of Islamic ethical values also aligns with arguments in previous business ethics research that employees' personal values determine their 
propensity to promote the well-being of other organizational members (Tang et al., 2008).

Previous research suggests several positive outcomes of Islamic ethical values, including higher organizational commitment (Yousef, 2000), loyalty (Ali \& Al-Kazemi, 2007), job involvement (Khan et al., 2015), innovation capability (Kumar \& Che Rose, 2010), and job satisfaction (Khan et al., 2015), as well as OCB (Alhyasat, 2012; Murtaza et al., 2016). However, it has not considered the usefulness of an Islamic work ethic for mitigating the likelihood that employees avoid helping behaviors, in response to family obligations that interfere with their work.

To guide our theoretical arguments about the interactive effect of family-to-work conflict and Islamic work ethics on helping behavior, we draw from conservation of resources (COR) theory, which argues that employees are motivated to obtain and protect their resources (Hobfoll, 1989). A threat to or actual loss of resources generates stress, which motivates employees to avoid future resource losses (Beham, 2011; Hobfoll, 2001). When family obligations interfere with work for example, employees' resources "are lost in the process of juggling both work and family roles" (Grandey \& Cropanzano, 1999: 352). The motivation to prevent further resource loss then might drive them to withhold discretionary behaviors, such as helping other organizational members, when they suffer from family-to-work conflict (Witt \& Carlson, 2006). Accordingly, previous research identifies COR theory as an appropriate theoretical framework for examining the behavioral outcomes of conflicts between family and work domains (Beham, 2011; Grandey \& Cropanzano, 1999; Witt \& Carlson, 2006).

Notably, COR theory also predicts an important buffering role of employees' personal resources, which can help employees cope with situations that create resource losses (Abbas, Raja, Darr, \& Bouckenooghe, 2014; Hobfoll, 2001). Hobfoll (1989: 516) defines resources as "those objects, personal characteristics, conditions, or energies that are valued by the individual 
or that serve as a means for attainment of these objects, personal characteristics, conditions, or energies" and highlights in turn that "personal characteristics are resources to the extent that they generally aid stress resistance" (p. 517). Personal values, such as Islamic ethical values, can be considered part of this definition because an Islamic work ethic "has the capacity to protect one's self from organizational stressors" (Khan et al., 2015: 245). Similarly, Astakhova (2015) relies on COR theory to conceive of employees' collectivistic values as personal resources that influence the relationship between their work passion and OCB. Consistent with the COR-based argument that the depletion of energy resources due to stressful conditions may be countered by access to valuable personal resources (Witt \& Carlson, 2006), we propose that an Islamic work ethic buffers the negative relationship between family-to-work conflict and helping behavior.

In summary, we contribute to research that investigates the individual effects of familyto-work conflict and Islamic ethical values on the likelihood of employees engaging in OCB. To the best of our knowledge, previous research has not investigated the combined effects of these factors in a single study. The key contribution of this study therefore lies in its examination of how the likelihood that family obligations spill over to the workplace, in the form of lower helping behaviors, might be reduced by the presence of religiously based ethical values. The proposed buffering role of Islamic ethical values extends previous research on how these values protect employees from other stressful situations, such as perceived psychological contract breaches (Shah Bukhari et al., 2011) or unfair procedures or rewards (Khan et al., 2015). Moreover, by noting the potential moderating role of Islamic work ethics, we extend business ethics literature that generally has focused on the direct effect of religious-based values on OCB (Alhyasat, 2012; Kutcher et al., 2010; Murtaza et al., 2016). We thus respond to calls for contingency approaches to the study of Islamic ethical values (Khan et al., 2015). 


\section{Theoretical background and hypotheses}

Helping behaviors targeted at coworkers are intrinsically connected to workplace ethics (Deckop et al., 2003; Tang et al., 2008). For example, employees perceived as more ethical tend to engage in extra-role behaviors to a greater extent than those who are perceived as less ethical (Murtaza et al., 2016; Turnispeed, 2002). Even though helping behaviors might not always be ethical - actions targeted at promoting the well-being of certain coworkers might come at the expense of other members, for example - implicit in the very notion is the sense that personal values and ethics are instrumental for shaping this behavior (Tang et al., 2008; Turnispeed, 2002). Thus, the tendency of employees to go out of their way to help other organizational members complete their job tasks successfully constitutes a value-based phenomenon that relates closely to employees' own individual ethical beliefs (Deckop et al., 2003; Turnispeed, 2002). Previous business ethics studies thus identify helping behavior, or OCB in general, as a critical manifestation of ethical behavior in the workplace (Murtaza et al., 2016; Peloza \& Hassay, 2006; Rayner, Lawton, \& Williams, 2012).

In this study, we focus on the role of family-to-work conflict in shaping helping behavior. Conflict between work and family increasingly is acknowledged as an important determinant of employee attitudes and behavior (Bourhis \& Mekkaoui 2010; Cloninger, Selvarajan, Singh, \& Huang, 2015). For example, working long hours can have negative consequences for the quality of family life, which is a form of work-to-family conflict (e.g., Aluko 2009; Major, Klein \& Ehrhart, 2002). The stress that employees experience when they bring family-related strain to the workplace instead constitutes family-to-work conflict (e.g., Cordero, DiTomaso, Farris, \& Post 2009; Hammer, Bauer, \& Grandey, 2003). Prior research acknowledges the bidirectionality of conflict at the interface of work and family, such that work-to-family and family-to-work conflict 
can mutually inform each other (Boyar, Maertz, Pearson, \& Keough, 2003; Carlson \& Kacmar, 2000). For this study, we focus on the latter type, because the spillover of stress from family to work should be a particularly strong determinant of whether employees have sufficient residual energy to devote to helping behaviors that are not formally required by their employer (Frone, Russell, \& Cooper, 1992; Nohe et al., 2014). When family obligations negatively interfere with work, employees bring problems from home to the workplace, which may leave them struggling to meet their regular job requirements (Witt \& Carlson, 2006; Zhang et al., 2012) and with limited time to engage in voluntary activities. Thus, previous research shows that family-to-work conflict has a negative effect on the likelihood that employees go out of their way to help other organizational members (e.g., Amstad et al., 2011; Beham, 2011; Bragger et al., 2005).

The core premise of this study is that the negative effect of family-to-work conflict on helping behavior should be mitigated by Islamic work ethics—a set of moral principles that distinguish right from wrong in an Islamic context, encapsulating principles such as hard work, cooperation, creativity, and serving others (Ali \& Al-Owaihan, 2008; Beekun, 1997). In what follows, we first seek to replicate previous findings about the direct relationships of family-towork conflict and Islamic work ethics with the likelihood of employees to engage in voluntary work behaviors, though we also extend these studies by grounding our arguments for these relationships in COR theory. ${ }^{1} \mathrm{Next}$, and still drawing from COR theory, we hypothesize that the relationship between family-to-work conflict and helping behavior is moderated by an Islamic work ethic, such that this personal resource helps employees overcome the resource depletion that comes with the negative interference of their family with their work.

Family-to-work conflict and helping behavior

\footnotetext{
${ }^{1}$ Previous OCB research on the role of family-to-work conflict had relied on COR theory (e.g., Beham, 2011; Hammer et al., 2016), but COR theory applications to the study of Islamic work ethics are scarce.
} 
We predict a negative relationship between employees' perceptions of family-to-work conflict and their engagement in helping behaviors. According to the scarcity hypothesis, people's resource reservoirs are limited, so they need to maintain a balance between their family and work domains to fulfill their roles in both domains (Marks, 1977). When employees believe that their work functioning is significantly hampered by family obligations, their resource reservoirs become depleted, and they might have insufficient resources available to meet their regular job responsibilities (Netemeyer, Maxham, \& Pullig, 2005; Nohe et al., 2014; Witt \& Carlson, 2006). An important mechanism that connects family-to-work conflict with a reduced likelihood to invest significant efforts in voluntary helping behaviors thus is the motivation to conserve resources (Hobfoll, 2001). If it is difficult to meet their own work goals because of their preoccupations with family, employees likely focus on meeting formal job expectations, leaving little room for voluntary activities that contribute to the well-being of others (Witt \& Carlson, 2006). According to COR theory, employees whose resource reservoirs are depleted, irrespective of whether such resource depletion originates from within or outside the workplace, tend to avoid negative "resource loss spirals" (Hobfoll, 2001), as might arise if they invest significant time in activities that are not formally expected from their employer for example. Discretionary activities, such as taking ample time to listen to the concerns and problems of coworkers, demand significant energy (Paillé, 2011), and employees who feel drained at work because of severe family demands may not possess these resources (Witt \& Carlson, 2006).

Hypothesis 1: There is a negative relationship between employees' perceptions of family-to-work conflict and their helping behavior.

\section{Islamic work ethic and helping behavior}


We hypothesize a positive relationship between employees' Islamic work ethic and their helping behavior. The principles underlying the Islamic work ethic encourage employees to exhibit voluntarism, be cooperative when other people are in need (Yousef, 2000), and recognize the value of exerting diligent efforts that benefit fellow human beings (Ali, 2005). According to COR theory, employees who can draw from valuable personal resources are motivated to engage in positive work behaviors, because they anticipate that these behaviors can generate further resource gains, for themselves and for others (Hobfoll, 1989; Hobfoll \& Shirom, 2000). An Islamic work ethic thus should translate into an enhanced propensity to engage in positive work behaviors that increase the well-being of coworkers (Murtaza et al., 2016). Similarly, previous research indicates that a strong Islamic work ethic fuels a strong intrinsic joy when employees work hard and are generous in work efforts from which others can benefit (Ali, 1988; Ali \& AlOwaihan, 2008). Because people with a strong Islamic work ethic experience positive emotions when helping coworkers meet their job requirements (Ali, 2005), they should be motivated to go out of their way to assist coworkers (Hobfoll \& Shirom, 2000). Thus, employees with strong Islamic ethical values engage in helping behavior, because their values increase the personal satisfaction they derive from such behavior (Ryan \& Deci, 2000).

Hypothesis 2: There is a positive relationship between employees' Islamic work ethic and their helping behavior.

\section{Moderating role of Islamic work ethic}

We also consider the interactive effect of family-to-work conflict and an Islamic work ethic on helping behavior. Employees with high Islamic ethical values seemingly might be more sensitive to external threats to their work, because they feel a strong obligation to fulfill their formal job requirements (Ali \& Al-Owaihan, 2008; Yousef, 2000), in which case family 
interference with work might forcefully steer them away from voluntary helping behavior. Instead, we predict a buffering effect, for several reasons. First, following the logic of COR theory (Abbas et al., 2014; Hobfoll, 2001), a strong Islamic work ethic is a personal resource that can compensate for the resource loss caused by conflicting demands between family and work. To cope with the negative interference of family demands with work, employees benefit from their access to personal resources that protect them from family-related strains (Kahn, Wolfe, Quinn, Snoek, \& Rosenthal, 1964; Nohe et al., 2014; Witt \& Carlson, 2006). Because Islamic ethical values fuel employees' resource reservoirs and increase their persistence in seeking resolutions to challenging situations (Khan et al., 2015), they should decrease the likelihood that family-to-work conflict escalates and prevents employees from voluntarily helping their colleagues. Similarly, employees with a strong Islamic work ethic work hard and may identify different pathways to prevent family obligations from hindering their work activities (Ali, 2005), which further increases their ability to cope with the conflict.

Moreover, according to the principles underlying the Islamic work ethic, employees who can draw from Islamic ethical values are strongly committed to reach out to their colleagues and contribute to their success, irrespective of how doing so affects their own job situation (Ali \& AlOwaihan, 2008; Yousef, 2000). Notably, such helping efforts produce greater resource gains, in the form of personal satisfaction, for these employees when their helping efforts cannot be taken for granted (Yousef, 2001). Because employees with strong Islamic ethical values enjoy the challenge of finding solutions to adverse work situations, they should be particularly motivated to engage in voluntary helping behaviors when family stress spills over into their workplace (Hobfoll \& Shirom, 2000). That is, a strong Islamic work ethic should mitigate the potency with which family-to-work conflict reduces helping behavior, by increasing the joy that the employee 
derives from avoiding the negative effects of this adverse conflict situation. Similarly, employees who score high on the Islamic work ethic have a strong intrinsic motivation to exploit their skill set to deal with challenging situations (Khan et al., 2015; Ryan \& Deci, 2000). Therefore, they experience positive feelings of accomplishment when they can deal with these situations. In contrast, when employees score low on Islamic work ethics, they derive limited joy from working hard and tend to be more passive in their efforts to resolve adverse situations (Ali \& AlOwaihan, 2008), thereby reducing the likelihood that they will reach out to colleagues and help them in their work endeavors in the presence of significant family-to-work conflict.

Previous research also suggests that employees who score high on the Islamic work ethic exchange personal knowledge and experiences with colleagues about hardships they have faced (Murtaza et al., 2016). In turn, they can more readily express concerns about the resource depletion that they experience due to significant family demands (Witt \& Carlson, 2006), and colleagues can better understand and help address those concerns. Similarly, strong Islamic ethical values strengthen employees' intrafirm network relationships, creating more opportunities to seek others' advice about how to manage the negative interference of family with work (Ali, 1992). Overall, it becomes less likely then that employees find it unfeasible to engage in voluntary helping activities in the presence of resource-draining family-to-work conflicts (Hobfoll, 2001). The resource gains obtained from their peer interactions (Murtaza et al., 2016) — for example, insights that others in the organization face similar family-to-work issues and feelings of "being in the same boat" (Nahapiet \& Ghoshal, 1998)—should lower the likelihood that family-to-work conflict undermines voluntary helping behaviors (Hobfoll, 2001). Finally, Islamic ethical values stimulate innovation capabilities (Kumar \& Che Rose, 2010), so they should help employees find creative solutions for engaging in discretionary behaviors that 
are not formally rewarded, even when confronted with the severe interference of family demands with their work. Conversely, in the absence of a strong Islamic work ethic, the resource depletion that comes with family-to-work conflict is more difficult to resolve (Murtaza et al., 2016; Nohe et al., 2014), and the likelihood that such conflict diminishes voluntary efforts to help colleagues then increases.

Hypothesis 3: The negative relationship between employees' perceptions of family-towork conflict and their helping behavior is moderated by their Islamic work ethic, such that the relationship is weaker at higher levels of an Islamic work ethic.

\section{Research method}

Sample and data collection

The data for this study came from several organizations, based in Pakistan and operating in different sectors, such as chemistry, construction, finance, and education. Access to the organizations was facilitated by the personal and professional contacts of one of the coauthors. The process consisted of two paper-and-pencil surveys: one distributed to employees and another to the employees' supervisors. English is the official language of correspondence in most professional organizations in Pakistan, as well as the official language of instruction in high schools and universities, so the survey questions were in English.

For both surveys, cover letters explained the purpose of the study and assured the participants of the complete confidentiality of their responses. In particular, they were assured that responses would only be accessible to the research team, that no information at the individual level would ever be made public, and that only aggregate data would be accessible to people beyond the research team. Moreover, we indicated in the surveys that there were no correct or incorrect answers, and we asked respondents to answer the questions as honestly as possible. These two measures diminish concerns of social desirability or acquiescence biases 
(Spector, 2006). Before gathering employees' perceptions about the presence of family-to-work conflict and assessing their Islamic ethical values, we ensured that all respondents were Muslim. The second survey asked supervisors to rate the helping behaviors of their employees. Of the 290 surveys distributed, we received 222 completed pairs, representing 45 supervisors, which reflects a response rate of $77 \%$. Among the respondents, $23 \%$ were women, their average age was 32 years, and 35\% had a bachelor degree or lower, $44 \%$ had a master degree, and $21 \%$ had a doctoral degree. Further, 59\% of the respondents held a staff position without managerial responsibilities, whereas $41 \%$ held managerial positions.

\section{Measures}

The measures of the three focal constructs contained items from previous research and used five-point Likert scales, ranging from 1 ("strongly disagree") to 5 ("strongly agree").

Helping behavior. For the dependent variable, we used the extent to which employees go out of their way to help other organizational members, with a four-item scale from previous research (Tang et al., 2008). Sample items include, "This employee helps others who have been absent" and "This employee helps others who have heavy workloads" (Cronbach's alpha $=.80$ ).

Family-to-work conflict. To assess family-to-work conflict, employees indicated the extent to which there was negative interference of their family obligations with their functioning at work. We applied a five-item scale used in previous studies (Jawahar, Kisamore, Stone, \& Rahn, 2012; Netemeyer et al., 1996). Two example items are, "Family-related strain interferes with my ability to perform job-related duties" and "I have to put off doing things at work because of demands on my time at home" (Cronbach's alpha $=.87$ ).

Islamic work ethic. We also applied the well-established, 17-item scale of Islamic work ethic that has been used in many previous studies (e.g., Ali, 1992, Khan et al., 2015; Murtaza et 
al., 2016). Employees rated the following statements for example: "Dedication to work is a virtue," "Human relations in organizations should be emphasized and encouraged," "Creative work is a source of happiness and accomplishment," and "Justice and generosity in the workplace are necessary conditions for society's welfare" (Cronbach's alpha $=.77){ }^{2}$

Control variables. We considered several control variables to account for alternative explanations of helping behavior: gender $(1=$ female $)$, because women may be more altruistic than men (Belansky \& Boggiano, 1994); age (in years), because older employees may be more likely to consider helping behaviors as a moral obligation (Kanungo \& Conger, 1993); education (three-point scale, indicating bachelor or lower, master, or doctorate), because more educated employees may be more skilled in finding ways to help others (Pooja, De Clercq, \& Belausteguigoitia, 2016); and job level ( 0 = staff position; 1 = managerial position), because employees in higher positions tend to have less specific performance requirements (Wall, Cordery, \& Clegg, 2002) and thus more opportunities to undertake behaviors that go above and beyond their formal job descriptions (Ye, Cardon, \& Rivera, 2012). Following Becker's (2005) recommendation to omit control variables that may partial out true variance from the relationships of interest, we undertook a preliminary analysis to check for differences in helping behaviors for these four controls. An analysis of variance indicated significant differences in helping behavior for education $(p<.05)$ and job level $(p<.05)$ but not for gender. We also found a significant correlation between age and helping behavior $(p<.01)$. Thus, we controlled for age, education, and job level in our models.

\section{Results}

\footnotetext{
${ }^{2}$ Because the two independent variables (family-to-work conflict and Islamic work ethic) were measured by the same respondent, we undertook a confirmatory factor analysis to check for discriminant validity. We found a strongly significant difference in the chi-square values of the constrained model in which the correlation between the two constructs was set to equal 1, versus the unconstrained model in which the correlation between the constructs was set free $\left(\Delta \chi^{2}(1)=251.29, p<.001\right)$, in support of discriminant validity (Anderson \& Gerbing, 1988).
} 
In Table 1, we provide the zero-order correlations and descriptive statistics, and in Table 2, we offer the regression results. Model 1 included the control variables, Model 2 added familyto-work conflict and Islamic work ethic, and Model 3 added the family-to-work conflict $\times$ Islamic work ethic interaction term, which we calculated after mean-centering its constitutive components (Aiken \& West, 1991). ${ }^{3}$

[Insert Tables 1 and 2 about here]

Model 1 indicated that helping behaviors were higher among employees who were younger $(\beta=-.021, p<.05)$ and had lower education levels $(\beta=-.175, p<.10)$. These somewhat surprising results suggest that younger employees may be motivated to engage in helping behaviors because they see these behaviors as instrumental for receiving something in return over time (Wagner \& Rush, 2000). More educated employees also may have more formal job responsibilities, which leaves them less time for voluntary helping behaviors.

In support of the prediction that employees' perceptions of the negative interference of family obligations with work turns them away from positive behaviors that are not formally required, Model 2 showed that family-to-work conflict related negatively to helping behavior ( $\beta$ $=-.300, p<.001)$, consistent with Hypothesis 1 . Model 2 also indicated support for a beneficial role of the Islamic work ethic: Employees were more likely to engage in helping behavior when they expressed strong Islamic ethical values $(\beta=.620, p<.001)$, in support of Hypothesis 2 .

In Model 3, we found support for the hypothesized buffering effect of the Islamic work ethic on the relationship between family-to-work conflict and helping behavior $(\beta=.220, p<$

\footnotetext{
${ }^{3}$ Because of the nested nature of the data, we checked whether it was appropriate to apply hierarchical linear modeling to test our hypotheses, by calculating the interclass coefficients for the family-to-work conflict variable, which arguably might be influenced by group-level phenomena. This was not the case for our sample. Rather, the ICC(1) value was lower than the recommended .25 cut-off value for large group effects (Murphy \& Myors, 1998), so no substantial variance in this variable could be attributed to group membership. Moreover, the ICC(2) value was lower than the recommended .70 cut-off value (Lebreton \& Senter 2008), indicating limited reliability for the group means of the family-to-work conflict variable.
} 
.05). The likelihood that increasing levels of family-to-work conflict would diminish helping behavior decreased when employees expressed stronger Islamic ethical values, in support of Hypothesis 3. To clarify the nature of this moderating effect, we plotted the effects of family-towork conflict on helping behavior at high and low levels of the Islamic work ethic in Figure 1, combined with a simple slope analysis (Aiken \& West, 1991). The results indicated that the relationship between family-to-work conflict and helping behavior was significant when an Islamic work ethic was low $(\beta=-.518, p<.001)$ but became not significant when it was high $(\beta$ $=-.078, n s)$, in further support of Hypothesis 3 .

[Insert Figure 1 about here]

\section{Discussion}

This study contributes to business ethics research by investigating the unexplored interactive effect of family-to-work conflict and an Islamic work ethic on helping behavior. The limited previous attention to this issue is somewhat surprising, especially in light of the recognition that spending significant time on voluntary activities can be highly challenging for employees when stressful situations at home spill over to the workplace (Beham, 2011; Bragger et al., 2005; Nohe et al., 2014, Zhang et al., 2012). Using COR theory as a conceptual anchor, this study reveals that reduced helping behavior, as a response to the resource depletion that comes with family-to-work conflict, is mitigated to the extent that employees can draw on the critical personal resource of an Islamic work ethic (Ali, 1988; Yousef, 2001). For business ethics research, we thus establish a revised and expanded understanding of the occurrence of helping behaviors in an organization's ranks.

The direct negative relationship between family-to-work conflict and helping behavior is consistent with previous studies of OCB (Amstad et al., 2011; Beham, 2011; Bragger et al., 
2005); more generally, it mirrors previous findings about the harmful effects of role conflict situations on positive work behaviors (Eatough, Chang, Miloslavic, \& Johnson, 2011). The mechanism underpinning this negative relationship is the resource conservation that employees seek when family obligations threaten their ability to perform their regular job tasks successfully (Hobfoll, 1989, 2001), such that they become less motivated to allocate significant energy resources to voluntary helping behaviors (Beham, 2011; Tang et al., 2008). The direct positive relationship between the Islamic work ethic and helping behavior, in turn, shows that employees with strong Islamic ethic values tend to be more supportive of their coworkers. This personal resource stimulates employees to collaborate and help others (Yousef, 2000), with a strong emphasis on positive deeds that benefit others (Ali, 2005; Murtaza et al., 2016). From a conceptual point of view, the positive relationship between an Islamic work ethic and helping behavior is also consistent with COR theory (Hobfoll, 1989; Hobfoll \& Shirom, 2000), in that employees with strong Islamic values derive resource gains from this behavior, in the form of intensive joy and personal satisfaction (Ali, 2005; Ali \& Al-Owaihan, 2008).

The principal insight from this study, however, is that an Islamic work ethic also plays a more indirect beneficial role, by mitigating the negative relationship between employees' perceptions of family-to-work conflict and helping behavior. The likelihood that employees refrain from helping other organizational members in the presence of negative interferences by family obligations with their work gets subdued when the associated resource depletion can be compensated for by the resource gains that come with an Islamic work ethic (Hobfoll, 2001). For example, employees with strong Islamic ethical values experience personal joy from undertaking helping behaviors in the presence of challenging work situations (Yousef, 2001). Their enhanced propensity to gain valuable knowledge resources through their interactions with like-minded 
peers further mitigates the translation of family-to-work conflict into reduced helping behavior (Murtaza et al., 2016). Finally, Islamic ethical values function as personal resources that make employees more innovative, finding novel ways to meet their formal job obligations in the presence of significant family demands and still find time to help others voluntarily (Kumar \& Che Rose, 2010). When they can draw on their Islamic ethical values, employees thus are better positioned to engage in voluntary behaviors that improve the work situation of their organizational peers, even in the presence of family-to-work conflict.

\section{Limitations and future research}

Some limitations of this study could be addressed by further research. First, in our crosssectional investigation, we focused on how family-to-work conflict influences helping behavior, with an assumption of causality, but the relationship could be subject to reverse causality. When employees help their peers undertake their job tasks, they may become energized (Podsakoff et al., 1997) and perceive less work stress, regardless of their family obligations. Longitudinal research designs could reveal the long-term, causal processes that link perceptions of family-towork conflict with helping behaviors and the role of Islamic ethical values in these processes.

Second, we considered only one, specific contingency factor, ignoring alternative potential buffers of the negative relationship between family-to-work conflict and helping behaviors. Other personal factors also could function as buffers, including employees' creative self-efficacy (Tierney \& Farmer, 2002) or resilience, which might enhance their ability to bounce back from adverse situations at home (Youssef \& Luthans, 2007). Moreover, contextual factors likely determine whether resource depletion, due to family obligations, diminishes helping behaviors, including whether employees believe they are rewarded fairly by their organization 
(Colquitt, Conlon, Wesson, Porter, \& Ng, 2001) or whether they share similar work goals with their peers (Nahapiet \& Ghoshal, 1998).

Third, this study centers on a sample of Pakistan-based organizations, so cultural factors may be relevant. Even though our theoretical arguments are not specific to this country, Pakistani culture is generally risk averse (Hofstede, 2001), such that employees may be hesitant to go out of their way to help coworkers on a voluntary basis if they lack confidence that they can meet their regular job requirements. In this sense, the relative usefulness and impact of religion-based ethical values in reducing the negative effects of family-to-work conflict on helping behavior may be more salient in our study context than it would be in more risk-prone countries, such as Western cultures. Cross-country comparisons could assess the relative importance of negative family-to-work interference for helping behaviors, as well as the potency of underlying moderators in this process, in different cultural contexts. Such comparisons also could reveal the potential buffering roles of ethical values inspired by religions other than Islam.

\section{Practical implications}

Our results show that the challenges stemming from family issues can have significant consequences for employees' helping behaviors; they particularly reveal the mitigating role of the personal resource of an Islamic work ethic in this process. Helping behaviors can encourage peer success, as well as benefit the organization and aid employees themselves. Yet significant barriers to such behaviors also arise, including the belief that limited time is available to engage in voluntary assistance when dealing with a highly demanding, resource-draining family life (Bragger et al., 2005). If organizations want to encourage helping behavior in their ranks, they should seek to reduce the negative interference between family and work. To reduce the likelihood that stress at home spills over to the workplace, organizations might promote more 
family-friendly supervision (Wang, Walumbwa, Wang, \& Aryee, 2013) and install supportive work-life balance measures (ten Brummelhuis \& van der Lippe, 2010).

Moreover, the results indicate that strong Islamic ethical work values may be particularly useful in organizations that cannot avoid spillovers of family-related stress into the workplace. Organizations should recognize that the escalation of family-to-work conflict, transforming into reduced helping behaviors, is less likely among employees with strong Islamic ethical values, because these values contribute to the satisfaction that employees derive from their behaviors in the presence of challenging work conditions. People who score high on the Islamic work ethic also tend to be more involved in their work, so they are better able to identify opportunities for making themselves immune to the negative spillovers of family obligations to the workplace, leaving more room for them to resolve the problems their colleagues might experience (Ali \& Al-Owaihan, 2008). Organizations then might benefit from predicting and assessing the personal satisfaction that employees derive from actively supporting their colleagues in the presence of challenging situations, due to their religion-inspired ethical values. To increase the likelihood that current and future employees who score high on Islamic ethical values engage in helping behaviors, organizations also might highlight the vast array of opportunities for such behaviors in different task areas, including those that interest each individual employee most.

\section{Conclusion}

Drawing from COR theory, the primary goal of this study was to investigate the interactive effect between family-to-work conflict and an Islamic work ethic in explaining helping behavior. The results indicate that perceptions of the negative interference of family obligations with work undermine employees' propensity to help their colleagues voluntarily, but this effect is mitigated when employees can draw on an Islamic work ethic. This personal 
resource makes employees more immune to the resource depletion that stems from strong family demands, and hence diminishes the likelihood that employees turn away from helping their coworkers. We therefore hope this study functions as a platform for further investigations of how organizations can stimulate helping behaviors within their ranks and in different religious contexts. 


\section{Compliance with ethical standards}

Conflict of interest: The authors declare that they have no conflict of interest.

Ethical approval: All procedures performed in studies involving human participants were in accordance with the ethical standards of the institutional and/or national research committee and with the 1964 Helsinki declaration and its later amendments or comparable ethical standards.

Informed consent: Informed consent was obtained from all individual participants included in the study. 


\section{References}

Abbas, M., Raja, U., Darr, W., \& Bouckenooghe, D. (2014). Combined effects of perceived politics and psychological capital on job satisfaction, turnover intentions, and performance. Journal of Management, 40, 1813-1830.

Ahmad, M. S. (2011). Work ethics: An Islamic prospective. International Journal of Human Sciences, 8(1), 851-859.

Aiken, L.S., \& West, S.G. (1991). Multiple regression: Testing and interpreting interactions. Newbury Park, CA: Sage.

Ali, A. (1988). Scaling an Islamic work ethic. Journal of Social Psychology, 128(5), 575-583

Ali, A. (1992). The Islamic work ethic in Arabia. Journal of Psychology, 126(5), 507-519.

Ali, A. (2005). Islamic perspective on management and organization. Cheltenham: Edward Elgar.

Ali, A., \& Al-Owaihan, A. (2008). Islamic work ethic: A critical review. Cross Cultural Management: An International Journal, 15(1), 5-19.

Ali, A.J., \& Al-Kazemi, A.A. (2007). Islamic work ethic in Kuwait. Cross Cultural Management: An International Journal, 14(2), 93-104.

Alhyasat, K.M.K. (2012). The role of Islamic work ethics in developing organizational citizenship behavior at the Jordanian Press Foundations. Journal of Islamic Marketing, 3, $139-154$.

Aluko, Y. (2009). Work-family conflict and coping strategies adopted by women in academia. Gender \& Behavior, 7(1), 2096-2124.

Amstad, F.T., Meier, L.L., Fasel, U., Elfering, A., \& Semmer, N.K. (2011). A meta-analysis of work-family conflict and various outcomes with a special emphasis on cross-domain versus matching-domain relations. Journal of Occupational Health Psychology, 16, 151-169.

Anderson, J.C., \& Gerbing, D.W. (1988). Structural equation modeling in practice: A review and recommended two-step approach. Psychology Bulletin, 1033, 411-423.

Astakhova, M.N. (2015). The curvilinear relationship between work passion and organizational citizenship behavior. Journal of Business Ethics, 130, 361-374

Bachrach, D.G., Powell, B.C., Collins, B.J., \& Richey, R.G. (2006). Effects of task interdependence on the relationship between helping behavior and group performance. Journal of Applied Psychology, 91(6), 1396-1405.

Becker, T. E. (2005). Potential problems in the statistical control of variables in organizational research: A qualitative analysis with recommendations. Organizational Research Methods, 8, $274-289$.

Beekun, R. (1997). Islamic business ethics. Herndon: IIIT.

Beham, B. (2011). Work-family conflict and organizational citizenship behaviour: Empirical evidence from Spanish employees. Community, Work \& Family, 14, 63-80.

Belansky, E. S., \& Boggiano, A. K. 1994. Predicting helping behaviors: The role of gender and instrumental/expressive self schemata. Sex Roles, 30, 647-661.

Borman, W. C., \& Motowidlo, S. J. (1993) . Expanding the criterion domain to include elements of contextual performance. In N. Schmitt \& W. C. Borman (Eds.), Personnel selection in organizations (pp. 71-98). San Francisco: Jossey-Bass.

Bourhis, A., \& Mekkaoui, R. (2010). Beyond work-family balance: Are family-friendly organizations more attractive? Relations Industrielles, 65(1), 98-117. 
Boyar, S. L., Maertz, Jr., Pearson, A. W., \& Keough, S. (2003). Work-family conflict: A model of linkages between work and family domain variables and turnover intentions. Journal of Managerial Issues, 25, 175-190.

Bragger, J.D.N., Rodriguez-Srednicki, O., Kutcher, E.J., Indovino, L., \& Rosner, E. (2005). Work-family conflict, work-family culture, and organizational citizenship behavior among teachers. Journal of Business and Psychology, 20, 303- 24.

Carlson, D.S., \& Kacmar, K.M. (2000). Work-family conflict in the organization: Do life role values make a difference? Journal of Management, 26(5), 1031-1054.

Choi, B.K., \& Moon, H. (2016). Prosocial motive and helping behavior: examining helping efficacy and instrumentality. Journal of Managerial Psychology, 31(2), 359-374.

Cloninger, P.A., Selvarajan, T.T., Singh, B., \& Huang, S. (2015). The mediating influence of work-family conflict and the moderating influence of gender on employee outcomes. International Journal of Human Resource Management, 26(18), 2269-2287.

Colquitt, J.A., Conlon, D.E., Wesson, M.J., Porter, C.O.L.H., \& Ng, K.Y. (2001). Justice at the millennium: A meta-analytic review of 25 years of organizational justice research. Journal of Applied Psychology, 86, 425-445.

Cordero, R., DiTomaso, N., Farris, G.F., \& Post, C. (2009). Work-family conflict and turnover intentions among scientists and engineers working in R\&D. Journal of Business Psychology, $24,19-32$.

Deckop, J.R., Cirka, C.C., \& Andersson, L.M. (2003). Doing unto others: The reciprocity of helping behavior in organizations. Journal of Business Ethics, 47(2), 101-113.

Eatough, E. M., Chang, C. H., Miloslavic, S.A., \& Johnson, R. E. (2011). Relationships of role stressors with organizational citizenship behavior: A meta-analysis. Journal of Applied Psychology, 96, 619-632.

Frone, M.R., Russell, M., \& Cooper, M.L. (1992). Antecedents and outcomes of work-family conflict: Testing a model of the work-family interface. Journal of Applied Psychology, 77, $65-78$.

Grandey, A., \& Cropanzano, R. (1999). The conservation of resources model applied to workfamily conflict and strain. Journal of Vocational Behavior, 54, 350-370.

Hammer, L. B., Bauer, T. N., \& Grandey, A. A. (2003). Work-family conflict and work related withdrawal behaviors. Journal of Business and Psychology, 17, 419-436.

Hammer, L.B., Johnson, R.C., Crain, T.L., Bodner, T., Kossek, E.E., et al. (2016). Intervention effects on safety compliance and citizenship behaviors: Evidence from the work, family, and health study. Journal of Applied Psychology, 101, 19 -208.

Hobfoll, S.E. (1989). Conservation of resources. A new attempt at conceptualizing stress. American Psychologist, 44, 513-524.

Hobfoll, S.E. (2001). The influence of culture, community, and the nested-self in the stress process: Advancing conservation of resource theory. Applied Psychology: An International Review, 50, 337-369.

Hobfoll, S.E., \& Shirom, A. (2000). Conservation of resources theory: Applications to stress and management in the workplace. In R.T. Golembiewski (Ed.), Handbook of organization behavior ( $2^{\text {nd }}$ ed., pp. 57-81). New York: Dekker.

Hofstede, G. (2001). Culture's consequences: Comparing values, behaviors, institutions and organizations across nations, $2 \mathrm{~d}$ ed. Thousand Oaks, CA: Sage Publications.

Hoption, C. (2016). The double-edged sword of helping behavior in leader-follower dyads. Leadership \& Organization Development Journal, 37(1), 13-41. 
Jawahar, I.M., Kisamore, J.L., Stone, T.H., \& Rahn, D.L. (2012). Differential effect of inter-role conflict on proactive individual's experience of burnout. Journal of Business Psychology, 27, 244-254.

Johnson, T. M., \& Grim, B. J. (2013). Global religious populations 1910-2010. The World's religions in figures: An introduction to international religious demography. New York: John Wiley \& Sons.

Kahn, R.L., Wolfe, D.M., Quinn, R., Snoek, J.D., \& Rosenthal, R.A. (1964), Organizational stress. New York: Wiley.

Kanungo, R. N., \& Conger, J. A. (1993). Promoting altruism as a corporate goal. Academy of Management Executive, 7, 37- 48.

Khan, K., Abbas, M., Gul, A., \& Raja, U. (2015). Organizational justice and job outcomes: Moderating role of Islamic work ethic. Journal of Business Ethics, 126, 236-246.

Kumar, N., \& Che Rose, R. (2010). Examining the link between Islamic work ethic and innovation capability. Journal of Management and Development, 29(1), 79-93.

Kutcher, E.J., Bragger, J.D., Rodriguez-Srednicki, O., \& Masco, J.L. (2010). The role of religiosity in stress, job attitudes, and organizational citizenship behavior. Journal of Business Ethics, 95, 319-337.

Lebreton, J.M., \& Senter, J.L. (2008). Answers to 20 questions about interrater reliability and interrater agreement. Organizational Research Methods, 11, 815-852.

Liang, H.-Y., Shih, H.-A., \& Chiang, Y.-H. (2015). Team diversity and team helping behavior: The mediating roles of team cooperation and team cohesion. European Management Journal, $33(1), 48-59$.

Major, V., Klein, K., \& Ehrhart, M. (2002). Work time, work interference with family, and psychological distress. Journal of Applied Psychology, 87(3), 427 -436.

Marks, S.R. (1977). Multiple roles and role strain: Some notes on human energy, time, and commitment. American Sociological Review, 42, 921-936.

Murphy, K.R., \& Myors, B. (1998). Statistical power analysis: A simple and general model for traditional and modern hypothesis tests. Mahwah, NJ: Lawrence Erlbaum.

Murtaza, G., Abbas, M., Raja, U., Roques, O., Khalid, A., \& Mushtaq, R. (2016). Impact of Islamic Work Ethics on organizational citizenship behaviors and knowledge-sharing behaviors. Journal of Business Ethics, 133, 325-333.

Nahapiet, J. \& Ghoshal, S. (1998). Social capital, intellectual capital, and the organizational advantage. Academy of Management Review, 23, 242-268.

Netemeyer, R., Boles, J., \& McMurrian, R. (1996). Development and validation of work-family conflict and family-work conflict scales. Journal of Applied Psychology, 81, 400-410.

Netemeyer, R.G., Maxham, J.G., III., \& Pullig, C. (2005). Conflicts in the work-family interface: Links to job stress, customer service employee performance, and customer purchase intent. Journal of Marketing, 69(2), 130-143.

$\mathrm{Ng}$, K.Y., \& Van Dyne, L. (2005). Antecedents and performance consequences of helping behavior in work groups: A multilevel analysis. Group \& Organization Management, 30(5), 514-540.

Ng, T.W.H., \& Feldman, D.C. (2012). Employee voice behavior: A meta-analytic test of the conservation of resources framework. Journal of Organizational Behavior, 33, 216-234.

Nohe, C., Michel, A., \& Sonntag, K. (2014). Family-work conflict and job performance: A diary study of boundary conditions and mechanisms. Journal of Organizational Behavior, 35(3), $339-357$. 
Organ, D. W. (1988). Organizational citizenship behavior: The good soldier syndrome. Lexington, MA: Lexington Books.

Paillé, P. (2011). Perceived stressful work, citizenship behaviour and intention to leave the organization in a high turnover environment: Examining the mediating role of job satisfaction. Journal of Management Research, 3, 1-16.

Peloza, J., \& Hassay, D.N. (2006). Intra-organizational volunteerism: Good soldiers, good deeds and good politics. Journal of Business Ethics, 64, 357-379.

Podsakoff, P.M., Ahearne, M., MacKenzie, S.B. (1997). Organizational citizenship behavior and the quantity and quality of work group performance. Journal of Applied Psychology, 82(2), 262-270

Pooja, A.A., De Clercq, D., \& Belausteguigoitia, I. (2016). Job stressors and organizational citizenship behavior: The roles of organizational commitment and social interaction. Human Resource Development Quarterly, 27, 373-405.

Rayner, J., Lawton, A., \& Williams, H.M. (2012). Organizational citizenship behavior and the public service ethos: Whither the organization? Journal of Business Ethics, 106, 118-130.

Rispens, S. (2009). Do fights prohibit helping? The influence of task interdependence and conflict norms on helping behavior during task conflict. International Journal of Conflict Management, 20(2), 158-172.

Ryan, R.M., \& Deci, E.L. (2000). Self-determination theory and the facilitation of intrinsic motivation, social development, and well-being. American Psychologist, 55(1): 68-78.

Seo, J.Y., \& Scammon, D.L. (2014). Does feeling holier than others predict good deeds? Selfconstrual, self-enhancement and helping behavior. Journal of Consumer Marketing, 3(6/7), 441-451.

Shah Bukhari, T.A., Saeed, M.M., \& Nisar, M. (2011). The effects of psychological contract breach on various employee level outcomes: The moderating role of Islamic work ethic and adversity quotient. African Journal of Business Management, 5(21), 8393-8398.

Spector, P.E. (2006). Method variance in organizational research: Truth or urban legend? Organizational Research Methods, 9, 221-232.

Stock, R.M. (2015). Is boreout a threat to frontline employees' innovative work behavior? Journal of Product Innovation Management, 32, 574-592.

Tang, T.L.-P., Sutarso, T., Wu Davis, G M.-T., Dolinski, D., Ibrahim, A.H.S., \& Wagner, S.L. (2008). To help or not to help? The Good Samaritan effect and the love of money on helping behavior. Journal of Business Ethics, 82, 865-887.

ten Brummelhuis, L.L., \& van der Lippe, T. (2010). Effective work-life balance support for various household structures. Human Resource Management, 49(2), 173-193

ten Brummelhuis, L.L., van der Lippe, T., Kluwer, E.S. (2010). Family involvement and helping behavior in teams. Journal of Management, 36(6), 406-1431.

Tierney, P., \& Farmer, S.M. (2002). Creative self-efficacy: Potential antecedents and relationship to creative performance. Academy of Management Journal, 45, 1137-1148.

Turnipseed, D.L. (2002). Are good soldiers good? Exploring the link between organization citizenship behavior and personal ethics. Journal of Business Research, 55, 1-15.

Uddin, S. J. (2003). Understanding the framework of business in Islam in an era of globalization: A review. Business Ethics: A European Review, 12(1), 23-32.

Wagner, S.L., \& Rush, M.C. (2000). Altruistic organizational citizenship behavior: Context, disposition, and age. Journal of Social Psychology, 140, 379-391. 
Wall, T.D., Cordery, J.L., Clegg, C.W. (2002). Empowerment, performance, and operational uncertainty: a theoretical integration. Applied Psychology: An International Review, 51, 146169.

Wang, P., Walumbwa, F.O., Wang, H., \& Aryee, S. (2013). Unraveling the relationship between family-supportive supervisor and employee performance. Group \& Organization Management, 38(2), 258-287.

Witt, L.A., \& Carlson, D.S. (2006). The work-family interface and job performance: Moderating effects of conscientiousness and perceived organizational support. Journal of Occupational Health Psychology, 11, 343-357.

Ye, J., Cardon, M.S., \& Rivera, E. (2012). A mutuality perspective of psychological contracts regarding career development and job security. Journal of Business Research, 65, 294-301.

Yousef, D. A. (2000). Organizational commitment and job satisfaction as predictors of attitudes toward organizational change in a non-western setting. Human Relations, 53, 513-537.

Yousef, D. A. (2001). Islamic work ethic: A moderator between organizational commitment and job satisfaction in a cross-cultural context. Personnel Review, 30, 152-164.

Youssef, C. M., \& Luthans, F. (2007). Positive organizational behavior in the workplace: The impact of hope, optimism, and resiliency. Journal of Management, 33, 774-800.

Zhang, M., Griffeth, R.W., \& Fried, D.D. (2012). Work-family conflict and individual consequences. Journal of Managerial Psychology, 27(7), 696-713.

Zhu, Y., \& Akhtar, S. (2014). How transformational leadership influences follower helping behavior: The role of trust and prosocial motivation. Journal of Organizational Behavior, 35(3), 373-392. 
Figure 1: Moderating effect of Islamic work ethic on the relationship between family-to-work conflict and helping behavior

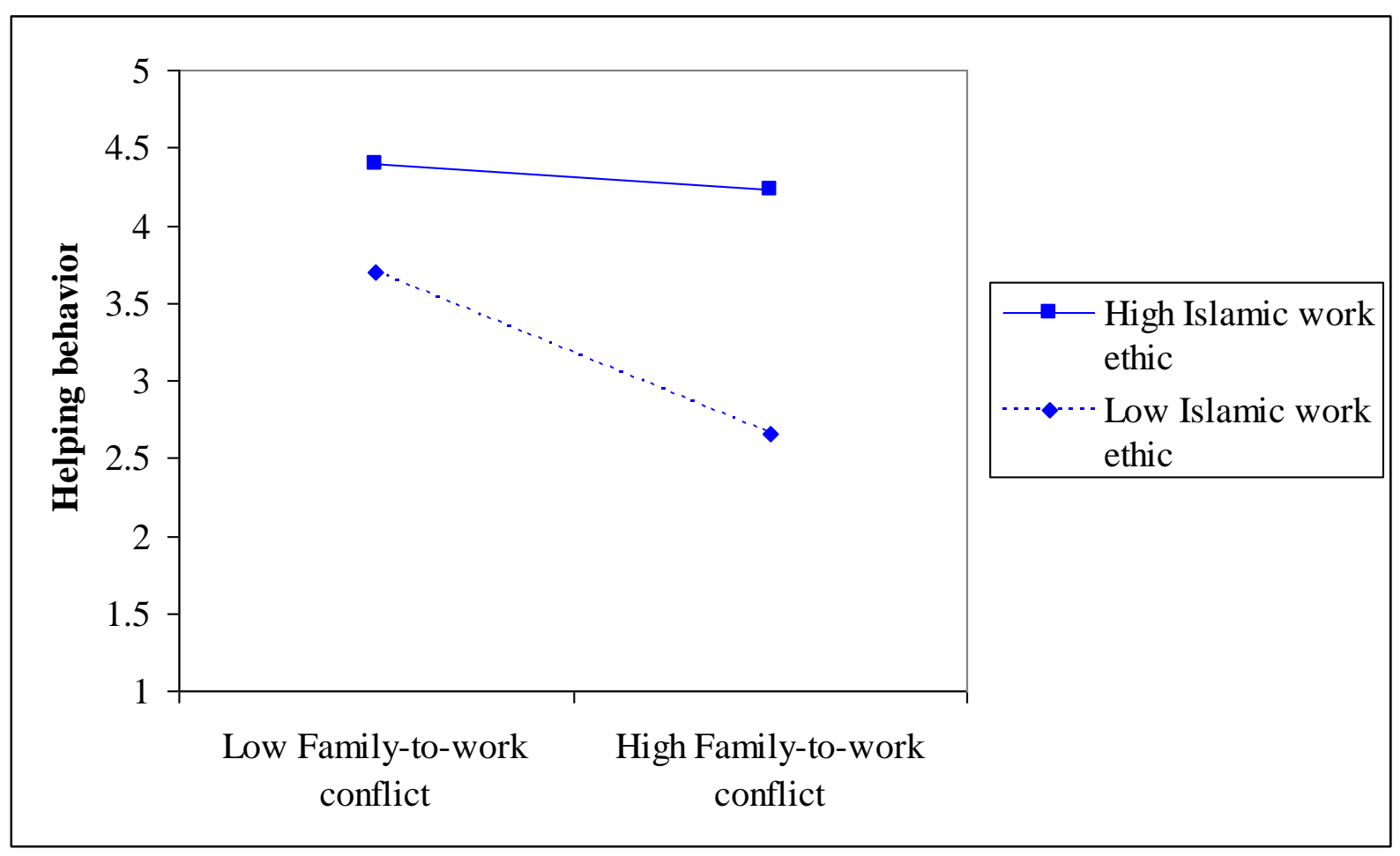


Table 1: Correlation table and descriptive statistics

\begin{tabular}{|c|c|c|c|c|c|c|c|c|}
\hline & Mean & SD & 1 & 2 & 3 & 4 & 5 & 6 \\
\hline 1. Helping behavior & 3.164 & 1.012 & & & & & & \\
\hline 2. Family-to-work conflict & 2.859 & .973 & $-.375 * *$ & & & & & \\
\hline 3. Islamic work ethic & 3.767 & .562 & $.380 * *$ & $-.244 * *$ & & & & \\
\hline 4. Age & 31.626 & 9.043 & $-.215 * *$ & .077 & .084 & & & \\
\hline 5. Education & 1.869 & .741 & $-.154 *$ & $.291 * *$ & $-.270 * *$ & .130 & & \\
\hline 6. Job level & .410 & .493 & $-.167 *$ & .068 & .080 & $.738 * *$ & $.135 *$ & \\
\hline
\end{tabular}

Notes: $\mathrm{N}=222$; education has three categories (bachelor or lower, master, or doctorate), and job level has two categories (staff position or managerial position).

$* * p<.01 ; * p<.05$ 
Table 2 : Regression results (dependent variable: helping behavior)

\begin{tabular}{lccc}
\hline & Model 1 & Model 2 & Model 3 \\
\hline Age & $-.021^{*}$ & $-.023^{*}$ & $-.021^{*}$ \\
Education & $-.175+$ & .074 & .085 \\
Job level & -.018 & -.064 & -.101 \\
$\mathrm{H}_{1}$ : Family-to-work conflict & & $-.300^{* * *}$ & $-.298^{* * *}$ \\
$\mathrm{H}_{2}$ : Islamic work ethic & & $.620^{* * *}$ & $.569^{* * *}$ \\
$\mathrm{H}_{3}$ : Family-to-work conflict $\times$ Islamic work ethic & & & $.220^{*}$ \\
\hline $\mathrm{R}^{2}$ & .062 & .280 & .293 \\
$\mathrm{R}^{2}$ change & & $.218^{* * *}$ & $.013^{*}$ \\
\hline
\end{tabular}

Notes: $\mathrm{N}=222$.

$*^{* *} p<.001 ; * * p<.01 ; * p<.05 ;{ }^{+} p<.10$. 